\title{
M2 macrophages exhibit higher sensitivity to oxLDL-induced lipotoxicity than other monocyte/macrophage subtypes
}

Suleiman A Isa, José S Ruffino, Maninder Ahluwalia, Andrew W Thomas, Keith Morris and Richard Webb*

\begin{abstract}
Background: In obesity, phenotypic switches occur in macrophage populations such that the predominantly M2-polarised anti-inflammatory state seen in lean individuals changes to a predominantly M1-polarised pro-inflammatory state in those who are obese. However, the mechanisms by which these phenotypic shifts occur have not yet been fully elucidated.

Results: The effects of oxLDL (1-40 $\mu \mathrm{g} / \mathrm{ml} ; 24 \mathrm{~h})$ on several parameters relevant to the Unfolded Protein Response (UPR)-mediated lipotoxic effects of oxLDL (disruption of $\mathrm{ER} \mathrm{Ca}^{2+}$ handling; activation of the UPR transcription factor XBP-1; upregulation of the UPR target genes BiP and CHOP; apoptosis; cell viability) were investigated in human primary monocyte-derived macrophages, and also in monocyte-macrophages derived from the THP-1 monocytic cell line. A consistent pattern was observed: M2-polarised macrophages were more sensitive to the lipotoxic effects of oxLDL than either non-polarised macrophages or non-differentiated monocytic cells. Specifically, M2-polarised macrophages were the only cell type to undergo significantly increased apoptosis (Primary cells: $1.23 \pm 0.01$ basal; THP-1-derived: $1.97 \pm 0.12$ basal; $P<0.05$ in both cases) and decreased cell viability (Primary cells: $0.79 \pm 0.04$ basal; THP-1-derived: $0.67 \pm 0.02$ basal; $P<0.05$ in both cases) when exposed to oxLDL levels similar to those seen in overweight individuals (ie. $1 \mu \mathrm{g} / \mathrm{ml}$ ).

Conclusions: We propose that the enhanced susceptibility of M2-polarised macrophages to lipotoxicity seen in the present in vitro study could, over time, contribute to the phenotypic shift seen in obese individuals in vivo. This is because a higher degree of oxLDL-induced lipotoxic cell death within M2 macrophages could contribute to a decrease in numbers of $\mathrm{M} 2$ cells, and thus a relative increase in proportion of non-M2 cells, within macrophage populations. Given the pro-inflammatory characteristics of a predominantly M1-polarised state, the data presented here may constitute a useful contribution to our understanding of the origin of the pro-inflammatory nature of obesity, and of the pathogenesis of obesity-associated inflammatory disorders such as Type 2 Diabetes and atherosclerosis.
\end{abstract}

Keywords: alternative M2 monocyte/macrophage polarisation, UPR, oxLDL, lipotoxicity

\section{Background}

Obesity and associated disorders such as Type-2 Diabetes (T2D) and atherosclerosis are associated with elevated levels of many lipids (eg. increased circulating oxidized low-density lipoprotein (oxLDL) [1,2]), and with chronic inflammation [3]. This can lead to intracellular lipid accumulation in non-adipocyte cells, which can in turn

\footnotetext{
* Correspondence: rwebb@uwic.ac.uk

Cardiff School of Health Sciences, University of Wales Institute Cardiff, UWIC Llandaf Campus, CARDIFF CF5 2YB, UK
}

lead to cell death, a phenomenon known as "lipotoxicity" [2].

Due to their wide tissue distribution, monocyte/macrophages, which play vital roles in inflammation and the development of obesity, T2D and atherosclerosis [3], are involved in lipid accumulation within many tissues [4]. For example, the intracellular accumulation of oxLDL within macrophages is mediated by scavenger receptors (such as CD36, SR-A and possibly SR-BI, although the role of the latter is currently controversial [5]) recognizing altered 
molecular patterns present on oxLDL or other forms of modified lipoproteins such as acetylated LDL (as distinct from non-oxidised LDL), and facilitating its uptake [6].

Two distinct subpopulations of monocyte/macrophages have been identified that exhibit different physiological properties: Th1 cytokines (eg. interferon- $\gamma$ and interleukin-1 $\beta$ ) promote polarisation into proinflammatory "classical" (M1) macrophages, while Th2 cytokines (eg. interleukin-4, interleukin-13) induce polarisation into antiinflammatory "alternative" (M2) macrophages $[7,8]$. M2 differentiation is associated with suppressed release of pro-inflammatory mediators [8], enhanced oxidative metabolism [9], and increased mitochondrial biogenesis [10]. Conversely, reductions in M2 differentiation correlate with disruptions in cholesterol homeostasis and reverse cholesterol transport [11], and to increases in total body fat mass, adiposity, glucose intolerance, and insulin resistance [10]. These findings led Odegaard et al to suggest that "macrophage polarisation towards the alternative [M2] state may be a useful strategy for treating T2D" [10].

Macrophage populations resident in adipose tissue upon high-fat feeding exhibit an M1-predominant state different from that of the M2-predominant population residing in adipose tissue under normal dietary conditions [12]. Moreover, similar phenotypic shifts have been reported for free cholesterol-loaded peritoneal macrophages in-vitro [13]. Mechanisms responsible for such obesity-linked shifts to predominantly M1 cells include increased infiltration of M1 cells from the circulation [1], and differentiation of mesenchymal stem cells into M1 cells (or trans-differentation of M2 cells into M1 cells) within adipose tissue [11]. Also, circulating peripheral blood monocytes can be primed for differentiation into functionally distinct macrophage subpopulations in certain circumstances, such as PPAR $\gamma$-mediated priming of circulating monocytes for differentiation towards an antiinflammatory M2 macrophage phenotype $[8,14]$. However, additional mechanism(s) may also underpin the M2-to-M1 shifts seen within pre-existing macrophage populations during the development of obesity [4]; for example, a recent report has suggested that "lipidinduced toxicity is an important determinant of the obesity-linked proinflammatory switch in macrophage polarisation" [15].

The endoplasmic reticulum (ER) is a key organelle with regard to lipotoxicity in macrophages, as trafficking of free cholesterol to the ER membrane and incorporation of cholesterol into the normally cholesterol-poor ER membrane alters the physico-chemical properties of this membrane and leads to disruption of ER functions [16]. Disturbance of ER functions leads to the ER becoming overwhelmed with accumulated unfolded proteins, and under such conditions of ER stress, the cell responds by initiating an "unfolded protein response" (UPR [17]). The UPR involves either generalised inhibition of translation combined with specific upregulation of UPR genes that restore the ER's ability to function (eg. binding immunoglobulin protein (BiP; a.k.a. GRP78); [18]), or activation of the pro-apoptotic C/EBP homologous protein (CHOP) pathway [19] if these actions fail to resolve the original ER stress. Hence, UPRs lead either to restoration of normal cell physiology and cell survival, or to cell death [17]. Thus, excessive accumulation of cholesterol into macrophages can lead via UPR/CHOP-triggered apoptosis to lipotoxic macrophage cell death [20,21]; importantly, we and others have recently reported that oxLDL can trigger similar effects [22,23], due to liberation of free cholesterol from oxLDL particles that have been imported into macrophages, and trafficking of this free cholesterol to the ER membrane $[16,20,23]$.

In the present study, we hypothesised that differential sensitivity of M2 macrophages to elevated levels of oxLDL in obesity, and thus to more frequent lipotoxic cell death of M2 cells, may contribute to the decrease in proportion of M2 cells seen within the macrophage population in obese individuals. Thus, using both primary cells and cells derived from the THP-1 monocytic cell lineage, we aimed to evaluate whether oxLDL induced the UPR and lipotoxic apoptosis to the same extent in control and M2-polarised monocyte-derived macrophages.

\section{Results}

\section{i) Primary Cells}

\section{IL-13/Rosiglitazone induced upregulation of markers of the} M2 macrophage phenotype

Two markers of the M2 phenotype, MR and IL-1Ra [8], underwent significant increases in mRNA expression after treatment of human primary macrophages ( $\mathrm{hM} \Phi$ ) with IL-13 and rosiglitazone (see Methods; MR: $2.93 \pm$ 1.03 basal; IL-1Ra: $3.76 \pm 1.32$ basal; $\mathrm{P}<0.10$ in both cases; Figure 1a), while MCP-1 (a marker of the M1 phenotype) did not undergo any significant increase (data not shown). Hence, cells that had undergone this treatment were confirmed as exhibiting the M2 macrophage (hM2M $\Phi)$ phenotype. IL-13/rosiglitazone treatment did not have any significant effect on cell viability (data not shown).

\section{The lipotoxic effects of oxLDL in M2-polarised primary macrophages}

Because ER stress-mediated apoptosis depends on activation of Caspases-3 and -7 [24,25], we sought to determine the effect of oxLDL on apoptosis using a luminometric Caspase 3/7 assay. As shown in Figure 1c, hM2M $\Phi$ exhibited significantly higher levels of oxLDLinduced apoptosis $(1 \mu \mathrm{g} / \mathrm{ml}: 2.22 \pm 0.06$ basal; $40 \mu \mathrm{g} / \mathrm{ml}$ : $7.09 \pm 0.36$ basal $)$ than $\mathrm{hM} \Phi(1 \mu \mathrm{g} / \mathrm{ml}: 1.23 \pm 0.01$ 


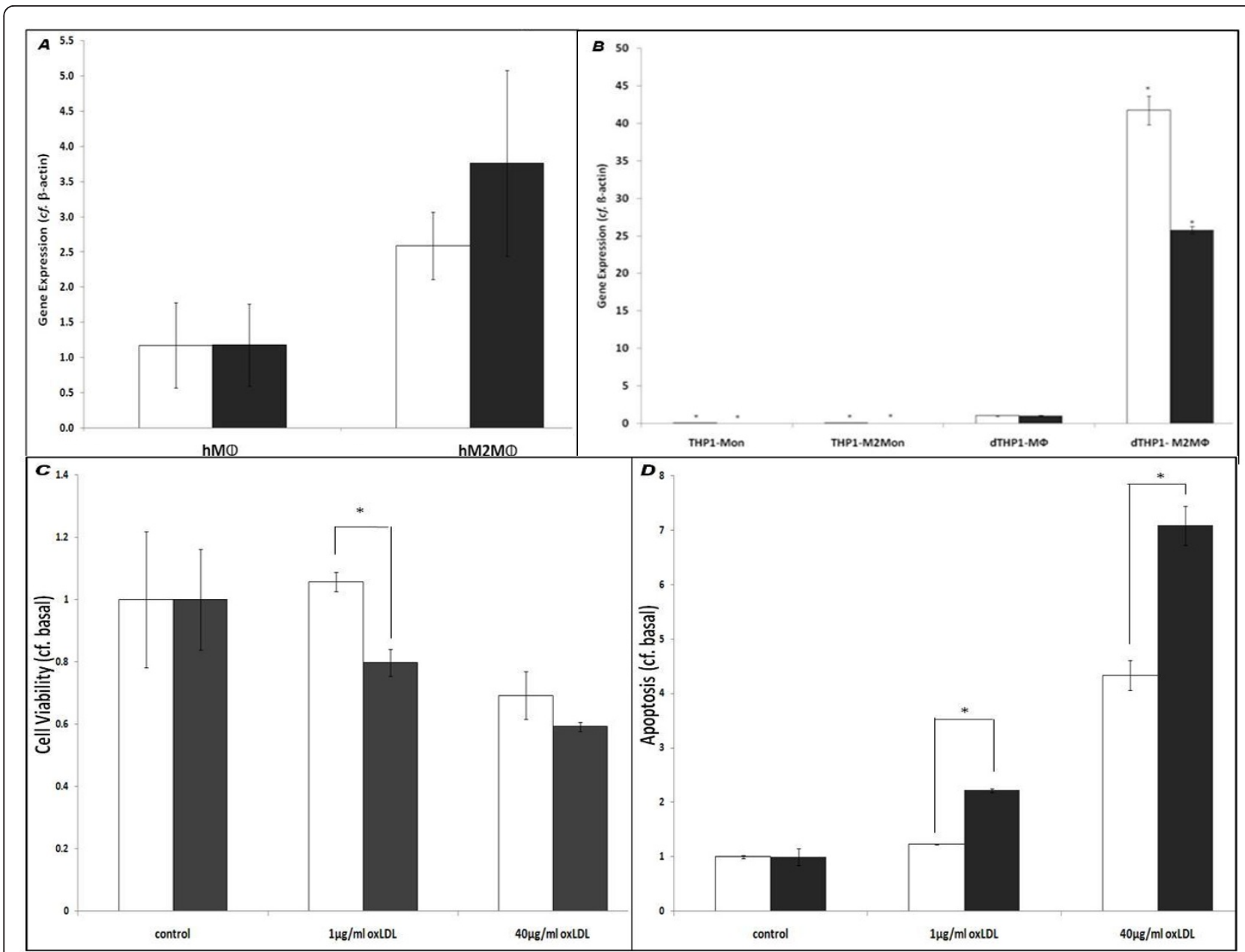

Figure 1 M2 polarisation and apoptosis/cell viability in primary macrophage cell types. A: RT-PCR was used to determine relative mRNA expression levels for the M2 markers MR (white bars) and IL-Ra (grey bars) before ('hM $M \Phi^{\prime}$ ) and after ('hM2M $\Phi^{\prime}$ ) treatment of human primary macrophages with $15 \mathrm{ng} / \mathrm{mL} \mathrm{IL}-13 / 1 \mu \mathrm{M}$ Rosiglitazone (72 h). $\mathrm{n} \geq 3$ in all cases; $\mathrm{P}<0.10$ where indicated. B: RT-PCR was used to determine relative mRNA expression levels for the M2 markers MR (white bars) and IL-Ra (grey bars) in THP1-Mon (white bars), THP1-M2Mon (light grey bars), dTHP1-MФ (dark grey bars) and dTHP1-M2MФ (black bars) $\mathrm{n} \geq 3$ in all cases; $\mathrm{P}<0.05$ where indicated. Spectrophotometric MTS assays (C) and luminometric Caspase 3/7 assays (D) were used to determine cell viability and apoptosis respectively in $\mathrm{hM} \Phi$ (white bars) and hM2M $\Phi$ (black bars), after treatment with oxLDL $(1 \mu \mathrm{g} / \mathrm{ml}$ or $40 \mu \mathrm{g} / \mathrm{ml} ; 24 \mathrm{~h})$ as indicated. $\mathrm{n} \geq 3$ in all cases.

basal; $40 \mu \mathrm{g} / \mathrm{ml}: 4.33 \pm 0.28$ basal; $P<0.05 \mathrm{hM} \Phi v$. hM2M $\Phi$ for both oxLDL doses). Similarly, as shown in Figure 1d, hM2M $\Phi$ exhibited more marked oxLDLinduced decreases in cell viability $(1 \mu \mathrm{g} / \mathrm{ml}: 0.79 \pm 0.04$ basal; $40 \mu \mathrm{g} / \mathrm{ml}: 0.59 \pm 0.02$ basal $)$, than hM $\Phi(1 \mu \mathrm{g} / \mathrm{ml}$ : $1.06 \pm 0.03$ basal; $40 \mu \mathrm{g} / \mathrm{ml}: 0.69 \pm 0.07$ basal; $\mathrm{P}<0.05$ hMФ $v$. hM2M $\Phi$ for $1 \mu \mathrm{g} / \mathrm{ml}$ oxLDL; non-significant for high oxLDL dose). Treatment with non-oxidised LDL did not elicit any increases in apoptosis or decreases in cell viability, whereas thapsigargin (100 nM; $24 \mathrm{~h})$, a "classical" inducer of ER stress [15], induced significant increases in apoptosis or decreases in cell viability in both cases (data not shown). Thus, these primary cell data suggest that M2-polarized cells are more sensitive than other forms of macrophage to the specific lipotoxic effects of oxLDL.

\section{ii) THP-1 derived cells}

To elucidate the mechanism underpinning the above effects, cells derived from the cultured monocytic THP1 cell line [26] were employed as models for primary monocyte-derived macrophages. The cell types used (see Methods section for details) were: THP-1 monocytic cells (THP1-Mon), M2-polarized THP-1 monocytes (THP1-M2Mon), PMA-differentiated THP-1 macrophages (dTHP1-MФ), and M2-polarized PMA-differentiated THP-1 macrophages (dTHP1-M2MФ). We have previously reported that intercalation of oxLDL-derived 
cholesterol into the ER membrane of oxLDL-treated THP1-Mon cells alters the physico-chemical properties of this membrane (as determined by Electron Paramagnetic Resonance spectrometry [23]), and so disrupts ER membrane protein function (as determined by coupledenzyme SERCA2b $\mathrm{Ca}^{2+}$ ATPase assays [23]).

\section{Expression of marker genes for the M2 macrophage phenotype}

As shown in Figure 1b, specific upregulation of two M2 markers, MR and IL-Ra [8], was observed after $72 \mathrm{~h}$ treatment of dTHP1-MФ with IL-13 and rosiglitazone (MR: $41.72 \pm 1.92$ basal; IL-1Ra: $25.76 \pm 0.48$ basal; $\mathrm{P}<$ 0.05 in both cases). Hence, cells that had undergone this treatment were confirmed as exhibiting an M2 macrophage-like (dTHP1-M2M 1 ) phenotype. In contrast, non-differentiated THP-1 monocytic cells expressed both marker genes only at very low levels in either the presence or the absence of IL-13/rosiglitazone treatment $(<0.1$ of that seen in dTHP1-MФ; Figure 1b). Once again, IL-13/rosiglitazone treatment did not have any significant effect on cell viability (data not shown).
Measurement of $\left[\mathrm{Ca}^{2+}\right]_{c y t}$

As shown in Figure 2, levels of resting $\left[\mathrm{Ca}^{2+}\right]_{\mathrm{cyt}}$, as measured by Fluo-3AM and converted to absolute $\left[\mathrm{Ca}^{2+}\right]_{\mathrm{cyt}}$ via the Grynkewickz equation [27,28], were within the expected physiological range (i.e. $<0.1 \mu \mathrm{M}$; [27]), indicating that this method could reliably be used for the estimation of $\left[\mathrm{Ca}^{2+}\right]_{\text {cyt }}$. Under conditions of increased ER membrane rigidity and disrupted ER membrane protein function, $\mathrm{Ca}^{2+}$ can escape from the ER into the cytoplasm $[17,29]$, and in our experiments, treatment with oxLDL $(24 \mathrm{~h})$ was associated with significant increases in $\left[\mathrm{Ca}^{2+}\right]_{\text {cyt }}$ (THP1-Mon: basal: $82 \pm 17 \mathrm{nM} ; 1$ $\mu \mathrm{g} / \mathrm{ml}: 144 \pm 30 \mathrm{nM} ; 40 \mu \mathrm{g} / \mathrm{ml}: 85 \pm 8 \mathrm{nM}$; $\underline{\mathrm{THP} 1-}$ M2Mon: basal: $38 \pm 6 \mathrm{nM} ; 1 \mu \mathrm{g} / \mathrm{ml}: 148 \pm 53 \mathrm{nM} ; 40$ $\mu \mathrm{g} / \mathrm{ml}: 102 \pm 16 \mathrm{nM}$; dTHP1-MФ: basal: $52 \pm 18 \mathrm{nM} ; 1$ $\mu \mathrm{g} / \mathrm{ml}: 105 \pm 33 \mathrm{nM} ; 40 \mu \mathrm{g} / \mathrm{ml}: 135 \pm 6 \mathrm{nM}$; dTHP1M2MФ: basal: $66 \pm 11 \mathrm{nM} ; 1 \mu \mathrm{g} / \mathrm{ml}: 81 \pm 1 \mathrm{nM} ; 40 \mu \mathrm{g} /$ $\mathrm{ml}: 85 \pm 4 \mathrm{nM}(\mathrm{P}<0.05 \mathrm{v}$. control in all cases, with the exception of THP1-Mon $/ 40 \mu \mathrm{g} / \mathrm{ml}$ oxLDL, where only a non-significant increase was seen)). $100 \mathrm{nM}$ thapsigargin induced significant increases in $\left[\mathrm{Ca}^{2+}\right]_{\mathrm{cyt}}$ in all cases (data not shown). Thus, oxLDL appeared to disrupt

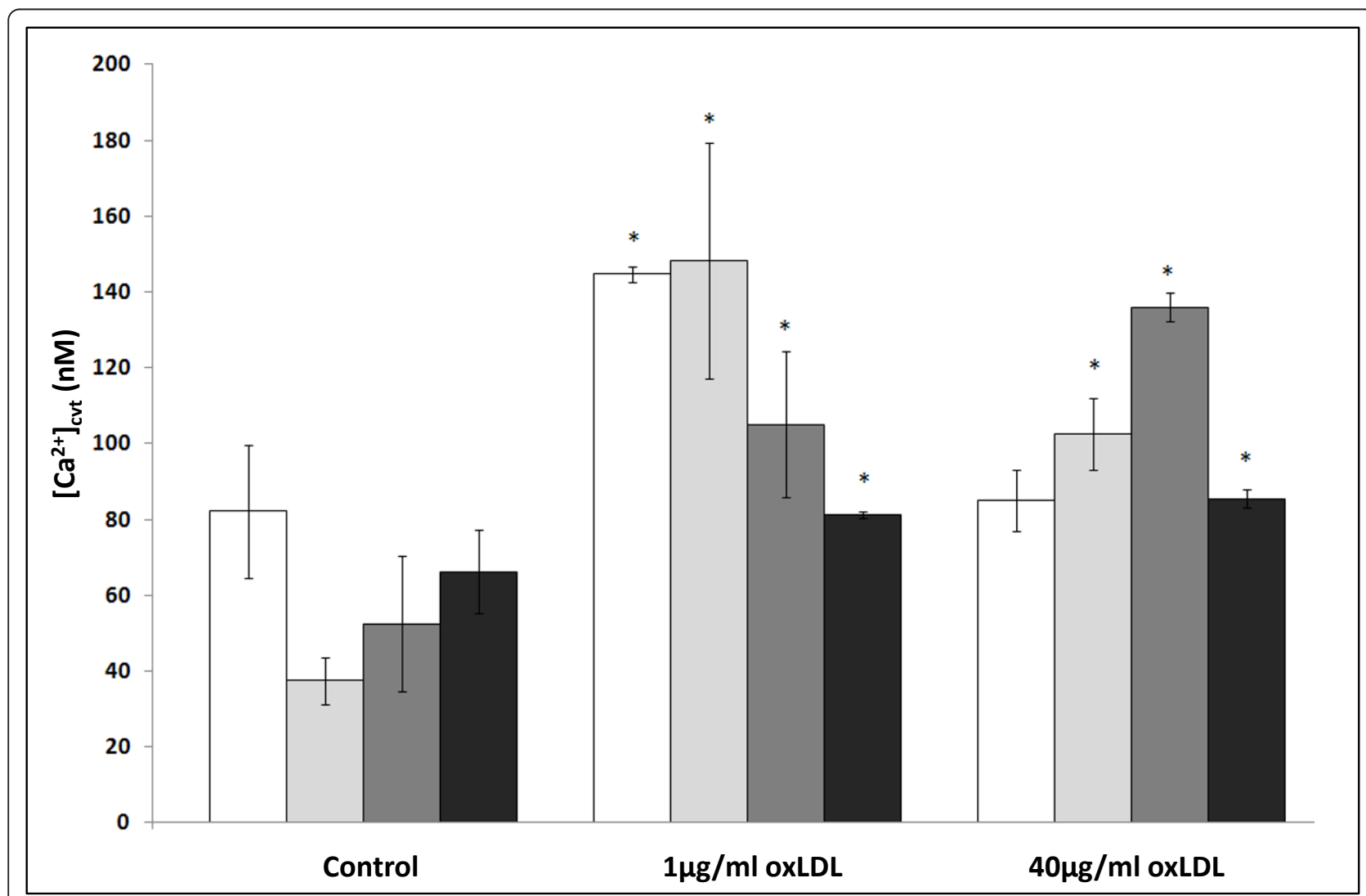

Figure 2 The effects of oxLDL on cytoplasmic $\mathrm{Ca}^{2+}$ concentrations in THP1-derived monocyte-macrophage cell-types. Fluo3-mediated

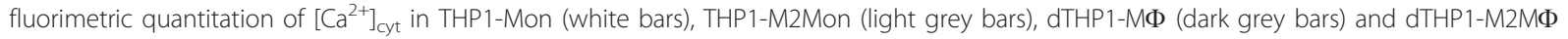
(black bars), after treatment with oxLDL $(1 \mu \mathrm{g} / \mathrm{ml}$ or $40 \mu \mathrm{g} / \mathrm{ml} ; 24 \mathrm{~h})$ as indicated. $\mathrm{n} \geq 3$ in all cases; $\mathrm{P}<0.05$ where indicated. 
cellular $\mathrm{Ca}^{2+}$ homeostasis, presumably via its actions on the ER, in all 4 cell types.

\section{Oxidized LDL-induced activation of XBP-1}

As alternative splicing (and hence activation) of the UPR transcription factor XBP-1 mRNA is an indicator of activation of the UPR in response to ER Stress [17], we employed the methods of Shang et al [30] to investigate XBP-1 splicing. Densitometric analysis showed neither $1 \mu \mathrm{g} / \mathrm{ml}$ nor $40 \mu \mathrm{g} / \mathrm{ml}$ oxLDL (24 $\mathrm{h}$ in both cases) induced XBP-1 activation in THP1-Mon, while in THP1-M2Mon (Figure 3b) there was XBP-1 activation only at high concentrations of oxLDL $(40 \mu \mathrm{g} / \mathrm{ml}: 1.79 \pm 0.20$ basal, $\mathrm{P}<0.05)$. In contrast, both oxLDL doses induced statistically significant XBP-1 activation in dTHP1-MФ ( $1 \mu \mathrm{g} / \mathrm{ml}: 1.28 \pm 0.12$ basal; 40 $\mu \mathrm{g} / \mathrm{ml}: 2.08 \pm 0.24$ basal; $\mathrm{P}<0.05$ in both cases; Figure $3 \mathrm{c}$ ), and dTHP1-M2MФ cells $(1 \mu \mathrm{g} / \mathrm{ml}: 1.60 \pm 0.20$ basal; 40 $\mu \mathrm{g} / \mathrm{ml}: 1.80 \pm 0.20$ basal; $\mathrm{P}<0.05$ in both cases; Figure $3 \mathrm{~d}$ ). As shown in Figure 3, thapsigargin (100 nM; $24 \mathrm{~h}$ ) induced significantly greater activation in all cases.

\section{Determination of $m R N A$ expression levels for the XBP-1 \\ Target Genes BiP and CHOP}

To confirm the previous identification of $\mathrm{BiP}$ and $\mathrm{CHOP}$ as UPR target genes ([18,19]; Figure 4a), we carried out bioinformatics screens of the BiP (Accession No: NM_005347.3) and CHOP (Accession No: NM_001195055.1) gene sequences. These revealed that within the 5'UTR of the BiP are three ER stress response elements (ERSEs) conforming to the consensus sequence $\operatorname{CCAAT}(n)_{x} \mathrm{CCACA}[18]$ at positions ${ }^{-283},{ }^{-316}$ and $^{-348}$, while within the CHOP 3'UTR is an ERSE conforming to the same consensus sequence [18] at position ${ }^{+661}$.

We then investigated the effects exerted by treatment with oxLDL ( $24 \mathrm{~h}$ ) on expression of $\mathrm{BiP}$ and $\mathrm{CHOP}$; while no oxLDL-induced BiP mRNA induction could be observed in THP1-Mon, oxLDL upregulated BiP at high oxLDL doses in THP1-M2Mon $(40 \mu \mathrm{g} / \mathrm{ml}: 1.81 \pm 0.13$ basal $(\mathrm{P}<0.05))$ and dTHP1-MФ $(40 \mu \mathrm{g} / \mathrm{ml}: 1.58 \pm 1.20$ basal $(\mathrm{P}<0.05))$, and at both oxLDL doses in dTHP1M2MФ $(1 \mu \mathrm{g} / \mathrm{ml}: 1.64 \pm 0.40$ basal; $40 \mu \mathrm{g} / \mathrm{ml}: 1.44 \pm 0.28$ basal $(\mathrm{P}<0.05$ in both cases $))$. Additionally, as shown in Figure $4 \mathrm{~b}$, oxLDL induced only non-significant CHOP upregulation in THP1-Mon, THP1-M2Mon and dTHP1МФ. In contrast, in dTHP1-M2MФ, low oxLDL doses induced non-specific increases in CHOP expression (1.40 \pm 0.68 basal; $\mathrm{P}>0.05)$, while high oxLDL doses significantly upregulated CHOP (3.09 \pm 0.93 basal; $\mathrm{P}<0.05)$. $100 \mathrm{nM}$ thapsigargin induced significantly greater $\mathrm{BiP} /$ CHOP upregulation in all cases (data not shown).

\section{oxLDL-induced ER stress-mediated apoptosis and} decreased cell viability

Because ER stress-mediated apoptosis depends on activation of Caspases-3 and -7 [24,25], we sought to determine the effect of oxLDL on apoptosis using a luminometric
Caspase 3/7 assay (Figure 5a). Treatment with oxLDL did not induce apoptosis in THP1-Mon or THP1-M2Mon, and induced only small non-significant increases in apoptosis in dTHP1-MФ. However, in dTHP1-M2MФ, oxLDL induced statistically significant increases in apoptosis $(1 \mu \mathrm{g} / \mathrm{ml}: 1.97 \pm 0.12$ basal; $40 \mu \mathrm{g} / \mathrm{ml}: 2.29 \pm 0.10$ basal; $\mathrm{P}$ $<0.05$ in both cases). Finally, the impact of oxLDLinduced apoptosis on cell viability was investigated: as shown in Figure 5b, no significant decrease in cell viability was observed with either oxLDL dose in either THP1-Mon or THP1-M2Mon. In contrast, both 1 and 40 $\mu \mathrm{g} / \mathrm{ml}$ oxLDL induced relatively small decreases in cell viability in dTHP1-MФ $(1 \mu \mathrm{g} / \mathrm{ml}: 0.78 \pm 0.07$-fold, $\mathrm{P}<$ 0.05; $40 \mu \mathrm{g} / \mathrm{ml}: 0.85 \pm 0.15$-fold; $\mathrm{P}>0.05)$, while inducing more marked decreases in cell viability in dTHP1M2MФ $(1 \mu \mathrm{g} / \mathrm{ml}: 0.67 \pm 0.02$-fold; $40 \mu \mathrm{g} / \mathrm{ml}: 0.58 \pm 0.02-$ fold; $\mathrm{P}<0.05$ in both cases; Figure $5 \mathrm{~b}) .100 \mathrm{nM}$ thapsigargin induced significantly greater increased apoptosis or decreased cell viability in all cases (data not shown). As with primary monocyte-derived macrophages, treatment with non-oxidised LDL did not elicit any increases in apoptosis or decreases in cell viability (data not shown).

Importantly, it should be noted that, with regard to apoptosis and cell viability, oxLDL-treated dTHP1M2MФ responded to a significantly greater extent than other cell-types ( $\mathrm{P}<0.05 \mathrm{v}$. oxLDL-treated THP1-Mon, THP1-M2Mon or dTHP1-MФ; Figure 5).

\section{Discussion}

The current study presents data indicating that M2polarised macrophages are more sensitive to the lipotoxic effects of oxLDL than other forms of monocyte/macrophage. The effects of oxLDL on disruption of ER $\mathrm{Ca}^{2+}$ homeostasis, activation of the UPR transcription factor $\mathrm{XBP}-1$, upregulation of the UPR target genes $\mathrm{BiP}$ and $\mathrm{CHOP}$, and on apoptosis and cell viability, were determined in six cell types: hMФ, hM2MФ, THP1-Mon, THP1-M2Mon, dTHP1-MФ, and dTHP1-M2MФ. With regard to these parameters, a consistent pattern was observed: THP1-Mon were the least sensitive to oxLDL, while hM2MФ and dTHP1-M2MФ were the most sensitive, with hMФ, dTHP1-MФ and THP1-M2Mon being intermediate in their sensitivity. Importantly, the M2polarised macrophages (hM2MФ and dTHP1-M2MФ) were the only cell types to undergo significantly increased apoptosis and decreased cell viability when exposed to oxLDL levels similar to those seen in the circulation of overweight individuals (ie. $\sim 1 \mu \mathrm{g} / \mathrm{ml}$ - as seen in individuals with a body mass index of $25-30 \mathrm{~kg} / \mathrm{m}^{2}$ [31]).

The source of oxLDL-induced lipotoxicity in this instance is likely to be cholesterol, a component of oxLDL particles. It has been known for many years that intracellular accumulation of cholesterol results when 


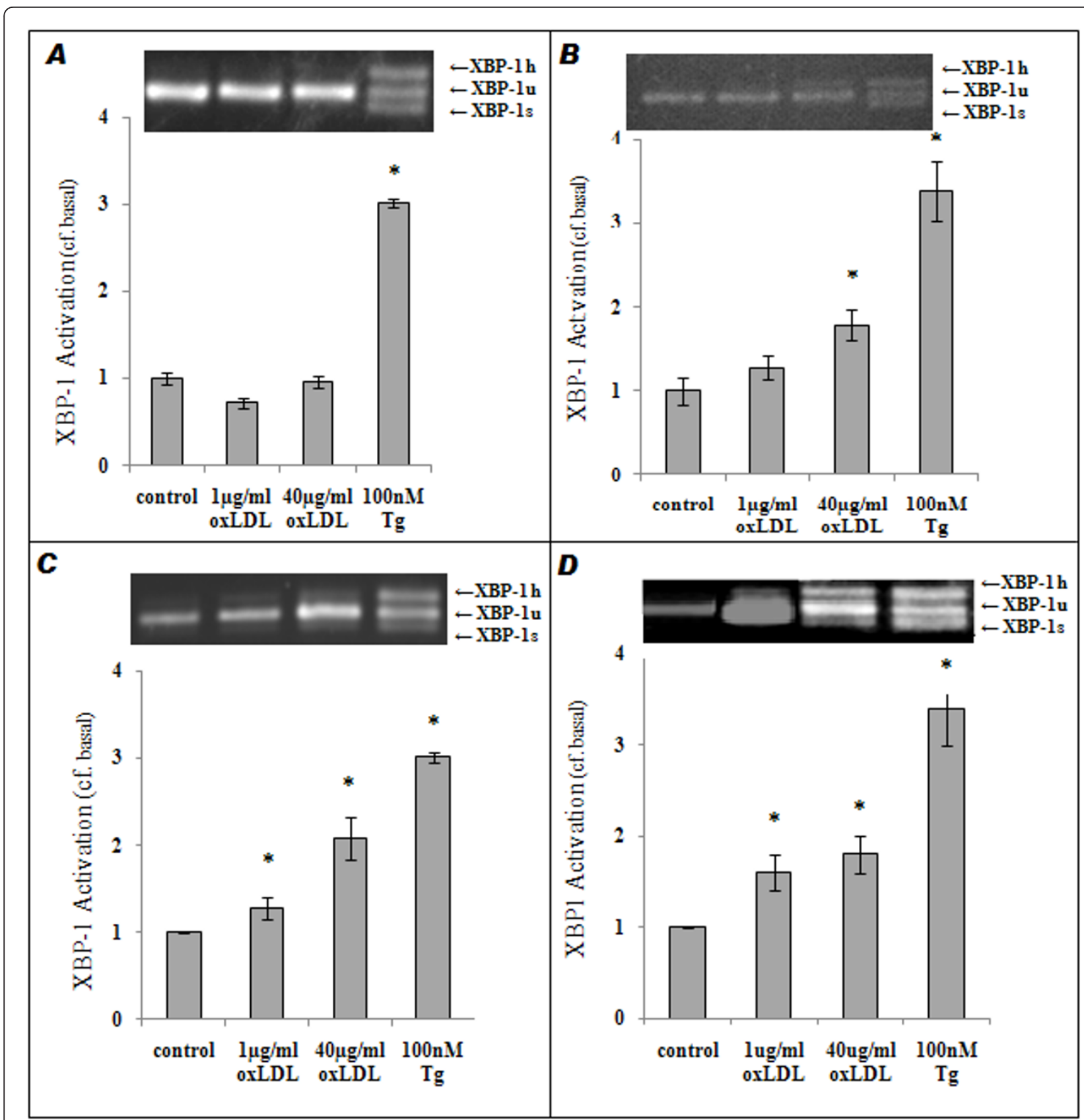

Figure 3 oxLDL-induced XBP-1 Activation in THP1-derived monocyte-macrophage cell-types. Representative images (insets) and densitometric summaries from agarose gels used to determine XBP-1 activation in THP1-Mon (A), THP1-M2Mon (B), dTHP1-MФ (C) and dTHP1M2MФ (D) after treatment with oxLDL $(1 \mu \mathrm{g} / \mathrm{ml}$ or $40 \mu \mathrm{g} / \mathrm{ml} ; 24 \mathrm{~h})$ or thapsigargin $(100 \mathrm{nM} ; 24 \mathrm{~h})$ as indicated. $\mathrm{n} \geq 3$ in all cases; $\mathrm{P}<0.05$ where indicated.

macrophages take in more lipid than can be excreted; lysosomal cholesterol esterases are responsible for the generation of free cholesterol from lipoprotein-derived cholesteryl esters, and a proportion of the resulting free cholesterol is trafficked to intracellular membranes such as the ER membrane [32]. The ER membrane is a narrow, fluid structure containing $<10 \%$ cholesterol [33]; elevation of its cholesterol content results in a broader, less fluid structure which restricts the ability of ER integral membrane proteins to undergo conformational movements and so catalyse their respective enzymatic reactions $[22,23]$. This results in disrupted ER function [23], and the resulting ER stress has been linked via the UPR/CHOP pathway to the triggering of apoptosis 


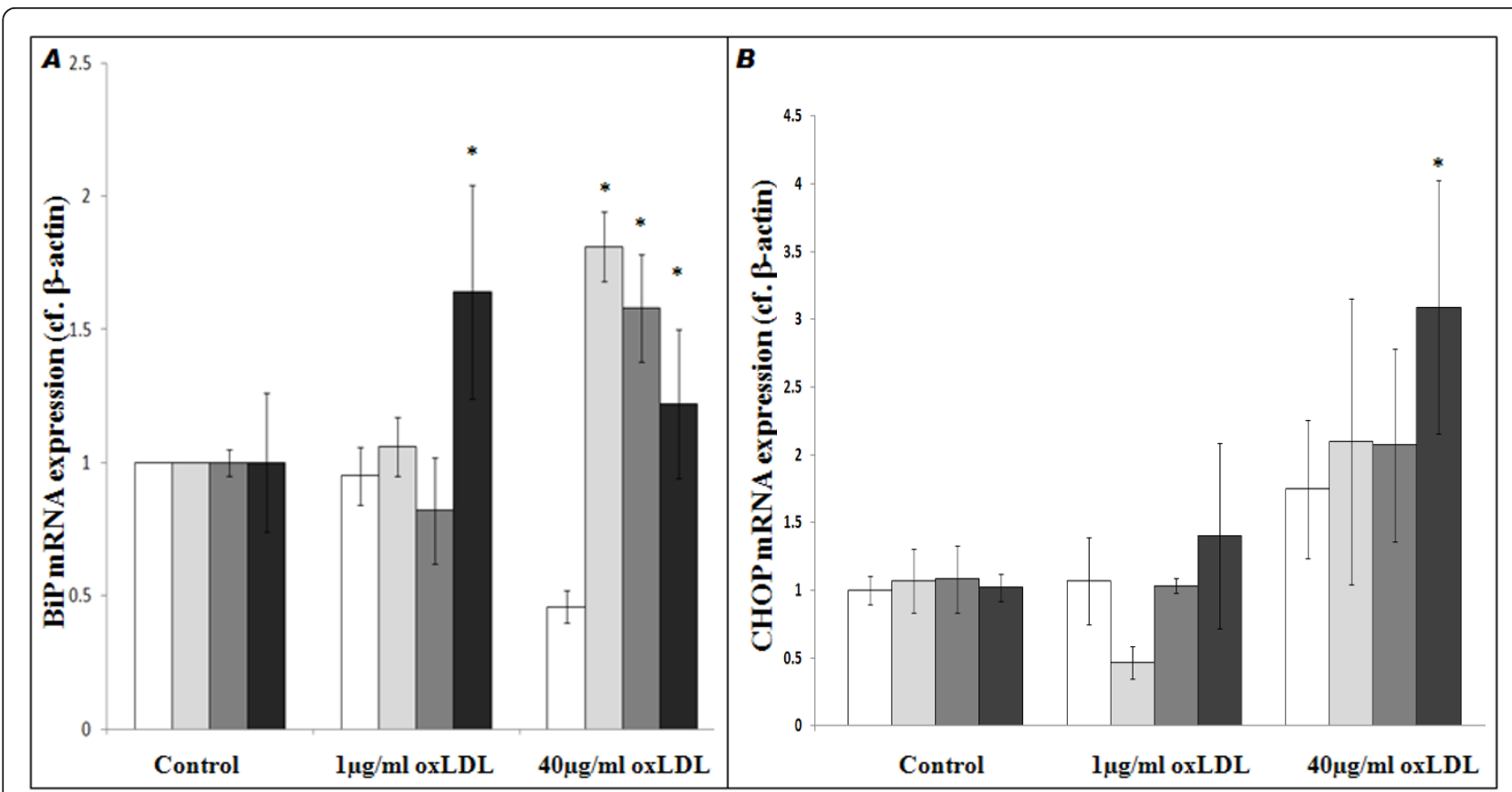

Figure 4 oxLDL-induced upregulation of the UPR target genes BiP and CHOP in THP1-derived monocyte-macrophage cell-types. Semiquantitative determination of $\mathrm{BiP}(\mathbf{A})$ and $\mathrm{CHOP}$ (B) mRNA levels in THP1-Mon (white bars), THP1-M2Mon (light grey bars), dTHP1-MФ (dark grey bars) and dTHP1-M2MФ (black bars), after treatment with oxLDL $(1 \mu \mathrm{g} / \mathrm{ml}$ or $40 \mu \mathrm{g} / \mathrm{ml} ; 24 \mathrm{~h})$ as indicated. $\mathrm{n} \geq 3$ in all cases; $\mathrm{P}<0.05$ where indicated.

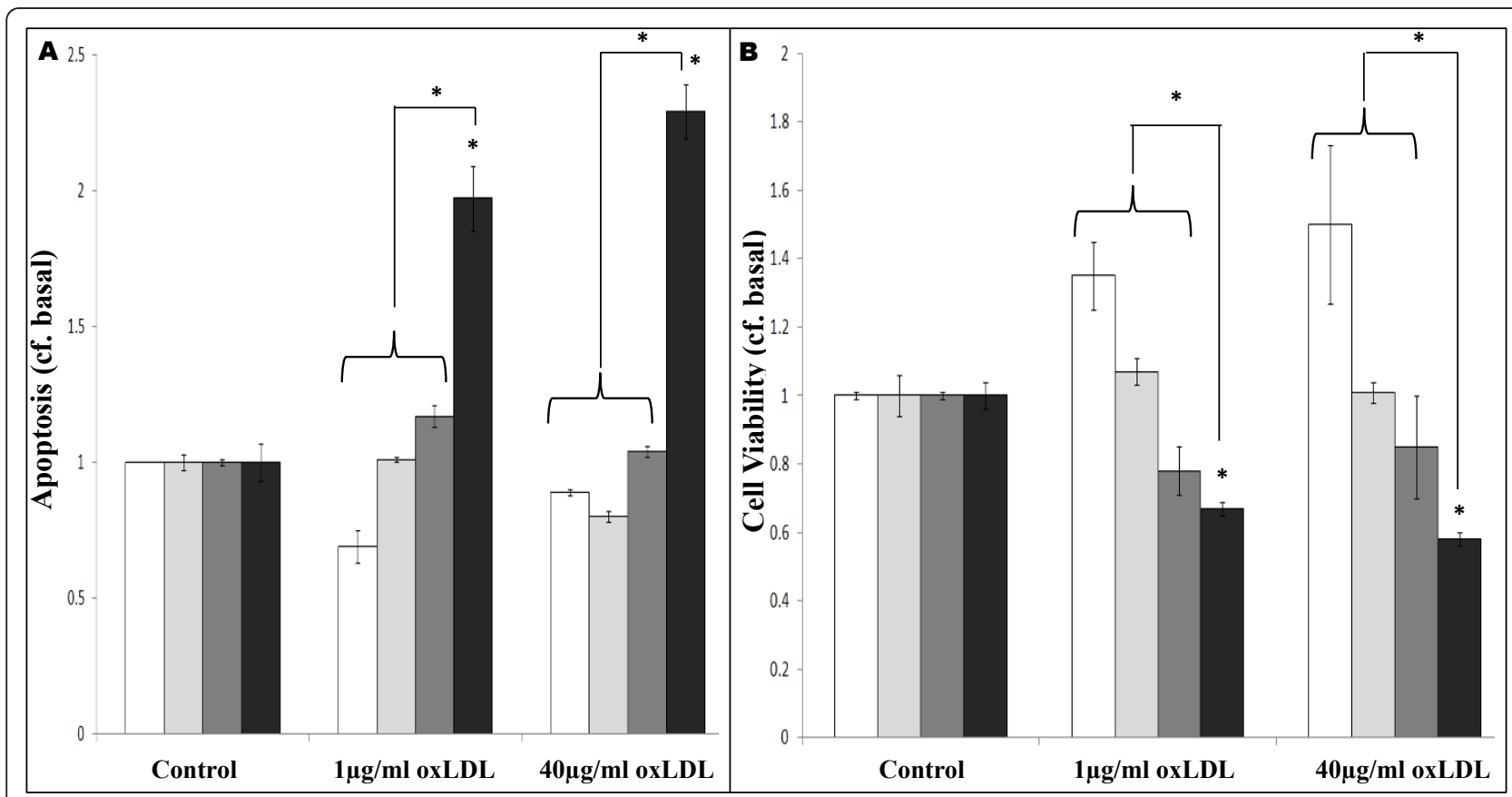

Figure 5 The effects of oxLDL on apoptosis and cell viability in THP1-derived monocyte-macrophage cell-types. Luminometric Caspase 3/7 and spectrophotometric MTS assays were used to determine apoptosis (A) and cell viability (B) respectively in THP1-Mon (white bars), THP1-

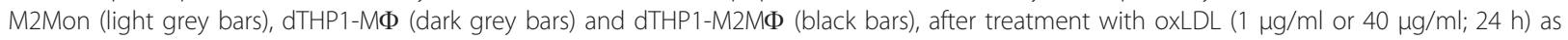
indicated. $\mathrm{n} \geq 3$ in all cases; $\mathrm{P}<0.05$ where indicated. 
$[19,20]$. Due to the presence of an ERSE in its 3'UTR (see Results section), CHOP mRNA can be induced by prolonged and/or severe ER stresses to act as a transcription factor that controls several genes associated with apoptosis, including Bcl-2, GADD34, TRB3 and several caspases, including caspases 3 and 7 [19]. (NB. It should be noted that the autophagic pathway, which can lead to non-apoptotic cell death by engulfing, degrading and recycling of cell organelles and proteins [34], is also associated with ER stress [35]; because in the present study, lipotoxic cell death associated with UPRs was assessed solely by determination of $\mathrm{CHOP}$ expression and caspase $3 / 7$ activity, the possibility cannot be ruled out that other forms of cell death may also play a role in obesity-related macrophage phenotypic shifts. Nevertheless, in line with several previous papers [19-22], the current study has focused on CHOP-mediated apoptosis as the predominant mode of lipotoxic cell death in macrophages.)

As stated above, several mechanisms that may contribute to the obesity-linked shift to predominantly M1 cells been identified $[1,11]$. However, additional mechanism(s) may also underpin the M2-to-M1 shifts seen within preexisting macrophage populations during the development of obesity [4], and as described above, lipotoxicity has recently been proposed as a potential mechanism by which such shifts may occur [15]. In the light of our demonstration that M2 macrophages exhibit higher sensitivity to oxLDL-induced lipotoxicity than non-M2polarised macrophages, we propose that a higher degree of oxLDL-induced lipotoxic cell death within M2 macrophages may contribute to the decrease in numbers of M2 cells. Over time, a relative increase in proportion of nonM2 cells and hence a predominantly M1 macrophage population would ensue, leading to development of a more pro-inflammatory milieu in the tissues of obese individuals.

Having demonstrated heightened sensitivity to oxLDLinduced lipotoxicity in M2-polarised macrophages, we next considered the possible sources of this heightened sensitivity (ie. we addressed the question: "At what point in the ER stress/lipotoxicity pathway do M2 cells become more sensitive?"). There were no significant differences in oxLDL's impact on $\left[\mathrm{Ca}^{2+}\right]_{\text {cyt }}$ in the different cell types (Figure 2), and dTHP1-M2MФ did not react to a greater extent than $\mathrm{dTHP} 1-\mathrm{M} \Phi$ in terms of XBP-1 activation (Figure 3). However, significant increases in BiP expression (cf. THP1-Mon) were only seen in dTHP1-M2MФ after treatment with $1 \mu \mathrm{g} / \mathrm{ml}$ oxLDL, with only non-significant increases being seen in other cell types (Figure 4a). Moreover, as shown in Figure 4b, statistically significant increases in CHOP expression were seen only in dTHP1M2MФ after treatment with $40 \mu \mathrm{g} / \mathrm{ml}$ oxLDL (a similar pattern was seen in the case of $1 \mu \mathrm{g} / \mathrm{ml}$ oxLDL $v$. CHOP, albeit without attaining statistical significance). Finally, with regard to apoptosis and cell viability, the response of dTHP1-M2MФ to oxLDL was significantly greater than the comparable responses of other THP-1 derived celltypes (Figure 5). As stated above, with regard to primary cells, the same general pattern was observed: hM2MФ exhibited significantly more apoptosis and less cell viability than hMФ when exposed to oxLDL levels similar to those seen in sedentary individuals (i.e. $1 \mu \mathrm{g} / \mathrm{ml}$ [31]; Figures 1c and 1d). Thus, it appears that a factor relevant to the UPR (perhaps involving differences in the ability of the UPR to restore normal cell physiology and so avoid the triggering of apoptosis) may be the source of M2-polarised cells' heightened lipotoxic sensitivity. Further elucidation of the source of this differential lipotoxicity may increase our understanding of the causal connections between obesity and inflammatory diseases such as T2D; however, definitive identification of this source is unfortunately beyond the scope of this preliminary study.

As stated above, macrophages are involved in lipid accumulation in a wide variety of tissues, including adipose tissue [12]. Intriguingly, quantitation of lipid-loading in different macrophage subtypes during the progression of obesity in $o b / o b$ mice fed a high-fat diet revealed that, while macrophage lipid-loading in general increased, very few lipid-loaded M2 macrophages could be identified, with lipid-loading and adoption of a foam cell-like appearance being characteristic only of M1 macrophages [15]. One may speculate that this could be explained by an inability of M2 macrophages to tolerate large quantities of intracellular lipid, and thus increased M2 cell death in a high-lipid environment. Such an explanation could also account for the high levels of apoptosis and M1-predominant nature of the macrophage foam cell populations resident in the unstable regions surrounding the lipid cores of atherosclerotic plaques $[8,21]$. Thus, the relevance of differential macrophage lipotoxicity is likely to extend beyond adipose tissue macrophages. For example, the M2to-M1 shift seen in Kupffer cells during the progression of liver steatosis has recently led Mandal et al to suggest that "changes in the M1/M2 phenotypic balance can impact on diverse disease conditions" [36], a statement which lends increased importance to the need to understand the mechanism(s) by which macrophage polarisation can be affected by phenomena such as lipotoxicity.

Clearly, there are several limitations to the current study (eg. the exclusively in vitro nature of the experiments; the lack of direct characterisation of differences in cholestero$l \rightarrow$ ER trafficking in each cell type). In particular, although the current study has specifically investigated the lipotoxic effects of oxLDL (and demonstrated that non-oxidised LDL is not associated with the same effects), it should also be recognised that in vivo, macrophages will be exposed to 
many other forms of lipid. Previous studies investigating different lipids have demonstrated the need to both activate the UPR/CHOP pathway and engage a scavenger receptor if apoptosis is to be triggered [20], suggesting that only lipoproteins that are ligands for scavenger receptors can trigger lipotoxic cell death. However, more recent studies have employed a lipidomic approach and found that a variety of lipid species underwent obesity-associated increases in levels within adipose tissue macrophages, and were associated with shifts towards the M1 phenotype; amongst these lipids were free cholesterol and saturated fatty acids [15]. Interestingly, the relatively rigid inflexible structures of both these lipids are compatible with disruption of ER membrane functions, and thus the triggering of the UPR. Meanwhile, lipids with more flexible structures that would not be expected to disrupt ER membrane properties (eg. polyunsaturated fatty acids, plasmalogens) were not associated with increases in the M1 subtype [15]. Thus, a capacity for triggering ER stress/UPR-linked apoptosis - and possibly a consequent heightened degree of damage to M2-polarised cells, which appear to be more sensitive to lipotoxicity - may underpin the detrimental effects of a variety of harmful lipids (including, but not limited to, oxLDL). Further studies are required to establish whether this is the case.

\section{Conclusion}

Given the elevated levels of circulating oxLDL and other lipids seen in obesity [2] (and hence the increased likelihood of the in vitro effects seen here occurring in the tissues of an obese individual in vivo), and also the importance of M1 macrophage-mediated inflammation in the pathogenesis of obesity-related diseases such as T2D and atherosclerosis [3], the current study's demonstration that M2-polarised macrophages are more sensitive to the UPR-mediated lipotoxic effects of oxLDL than other forms of monocyte/macrophage may constitute a useful contribution to our understanding of the origin of the pro-inflammatory nature of obesity, and of the pathogenesis of obesity-associated disorders such as T2D and atherosclerosis.

\section{Materials \& methods Materials}

All reagents were purchased from Sigma-Aldrich (Poole, UK) unless stated otherwise. oxLDL, rosiglitazone, GW9662 and IL-13 were obtained from Autogen Bioclear (Calne, UK), GlaxoSmithKline (Uxbridge, UK) and R\&D Systems (Abingdon, UK), respectively. Human primary monocyte-macrophages and human monocytic THP-1 cell lines were obtained from the Welsh Blood Transfusion Service (Llantrisant, UK) and European Collection of Cell Cultures (Salisbury, UK), respectively.

\section{Generation of primary human monocyte-derived macrophages}

Primary human monocyte-derived macrophages were obtained via the method of Iwashima et al [37]. Briefly, 10 $\mathrm{ml}$ of heparinised blood was diluted 1:1 in RPMI medium, layered over $10 \mathrm{ml}$ of Histopaque-1077 Ficoll-Hypaque and centrifuged at $400 \times \mathrm{G}$ for $20 \mathrm{~min}$. The mononuclear cell suspension was carefully removed from the FicollHypaque interface, and washed four times $(500 \times \mathrm{G}$; $10 \mathrm{~min}$ ) in Phosphate-Buffered Saline (PBS), and mononuclear cells were then incubated $\left(37^{\circ} \mathrm{C} ; 5 \% \mathrm{CO}_{2}\right)$ for $2 \mathrm{~h}$, after which non-adherent cells (representing non-monocytes) were removed by discarding the media. Following adhesion to tissue culture plasticware for 7 days (with medium being changed every $48 \mathrm{~h}$ ), monocytes were considered to have differentiated to human primary macrophages (hMФ). M2-polarized macrophages (hM2MФ) were then obtained via the method of Bouhlel et al [8], in which treatment for $72 \mathrm{~h}$ with $15 \mathrm{ng} / \mathrm{ml} \mathrm{IL}-13$ and $1 \mu \mathrm{M}$ rosiglitazone induced M2 polarization.

\section{Maintenance of THP-1 cells in culture}

Human THP-1 cells [25] were manipulated in culture in order to generate four distinct cell types: human THP-1 monocytic cells (THP1-Mon), M2-polarized THP-1 monocytes (THP1-M2Mon), PMA-differentiated THP-1 macrophages (dTHP1-MФ), and M2-polarized PMA-differentiated THP-1 macrophages (dTHP1-M2MФ). To generate THP1-M2Mon, dTHP1-MФ, and dTHP1M2MФ, the methods of Tjiu et al [38] and Bouhlel et al [8] were followed, with minor modifications: (a) THP1M2Mon: THP-1Mon cells were treated for $72 \mathrm{~h}$ with 15 ng/ml IL-13 and $1 \mu \mathrm{M}$ rosiglitazone; (b) dTHP1-MФ: THP-1Mon cells were treated with $100 \mathrm{ng} / \mathrm{ml}$ PMA for 72 $\mathrm{h}$; cells that adopted an adherent macrophage-like phenotype were selected as THP1MФ; (c) dTHP1-M2MФ: THP-1Mon cells were pre-incubated with $100 \mathrm{ng} / \mathrm{ml}$ PMA for $6 \mathrm{~h}$ before addition of $15 \mathrm{ng} / \mathrm{ml} \mathrm{IL}-13 / 1 \mu \mathrm{M}$ rosiglitazone for the remaining $66 \mathrm{~h}$ of a total incubation time of $72 \mathrm{~h}$.

\section{Cell treatments}

hMФ, hM2MФ, THP1-Mon, THP1-M2Mon, dTHP1MФ, and dTHP1-M2MФ were treated for $24 \mathrm{~h}$ with 1 $\mu \mathrm{g} / \mathrm{ml}$ oxLDL (which approximates to serum oxLDL levels seen in overweight individuals (ie. those with a body mass index of $25-30 \mathrm{~kg} / \mathrm{m}^{2}$ ) [31]) or $40 \mu \mathrm{g} / \mathrm{ml}$ oxLDL (a commonly-used supra-physiological dose [39]). In some cases, control samples were treated with nonoxidised LDL, or with thapsigargin $(100 \mathrm{nM})$ as a positive control for disruption of ER homeostasis [16], respectively. Data were expressed for each sample in comparison to the readings obtained in basal samples (ie. cells of 
the corresponding cell-type that had not been treated with oxLDL).

\section{Measurement of resting cytoplasmic $\mathrm{Ca}^{2+}$ concentrations $\left(\left[\mathrm{Ca}^{2+}\right]_{\text {cyto }}\right)$}

$\left[\mathrm{Ca}^{2+}\right]_{\text {cyto }}$ was measured by the method of Elsner [26], in which fluo-3 fluorescence was used as an indicator of resting $\left[\mathrm{Ca}^{2+}\right]_{\text {cyto. }}$. Adherent cells seeded into the wells of opaque-walled multi-well plates, (dTHP1-MФ, dTHP1M2M $\Phi$; approx $5 \times 10^{3}$ cells per sample), or cell suspensions (THP1-Mon, THP1-M2Mon; $7 \times 10^{6} / \mathrm{ml}$ in RPMI 1640) were pre-incubated with 1 or $40 \mu \mathrm{g} / \mathrm{ml}$ oxLDL for $24 \mathrm{~h}$ at $37^{\circ} \mathrm{C}$, and then incubated with $3 \mu \mathrm{M}$ fluo-3/AM (Molecular Probes, Eugene, OR) for $40 \mathrm{~min}$ at $37^{\circ} \mathrm{C}$ before washing twice with PBS; THP-1Mon and M2Mon samples were resuspended in RPMI 1640 at a final concentration of $1 \times 10^{6} / \mathrm{ml}$. Cell samples in multi-well plates were read using a Tecan Infinite ${ }^{\mathbb{B}} 200$ multimode microplate fluorimeter with a FITC filter $\left(\lambda_{\text {ex }}=490 \mathrm{~nm} ; \lambda_{\text {em }}=520 \mathrm{~nm}\right.$; Tecan, Dorset, UK). Using the Grynkiewicz equation, and previously reported values for Fluo-3's association constant with $\mathrm{Ca}^{2+}[27,28]$, fluorescence readings were then estimated as absolute $\mathrm{Ca}^{2+}$ concentration data.

\section{RNA extraction, and XBP-1 activation or gene expression RT-PCR assays}

In all cases, total RNA from hMФ, hM2MФ, THP1-Mon, THP1-M2Mon, dTHP1-MФ, and dTHP1-M2MФ ( \pm treatment with oxLDL or thapsigargin for $24 \mathrm{~h}$ as described above) were extracted with Trizol ${ }^{\circledR}$ Reagent (Invitrogen, Paisley, UK), and RNA samples were converted to cDNA using an Applied Biosystems ${ }^{\circledR}$ HighCapacity cDNA Reverse transcription Kit (Invitrogen, Paisley, UK), according to the manufacturer's instructions. Activation of the UPR transcription factor XBP-1 was assessed via Shang's method [30], which uses RT-PCR, agarose gel electrophoresis and densitometric analysis to determine XBP-1 activation. Because Ire1's endoribonuclease activity excises a 44 bp segment from within exon 4 of the unspliced XBP-1 mRNA species (XBP-1(u); Accession No: NM_005080.3) under conditions of ER stress, and so generates a spliced mRNA (XBP-1(s); Accession No: NM_001079539.1) encoding the active form of the protein [14], XBP-1 activation was determined via densitometric analysis of banding patterns on $2 \%$ agarose gels by means of the following formula "[XBP-1(s)+0.5 XBP-1 (h)]/[XBP-1(s)+XBP-1(h)+XBP-1(u)]", where XBP-1(s) is a 398 bp PCR product, XBP-1(u) is a 442 bp PCR product, and $\mathrm{XBP}-1(\mathrm{~h})$ is an additional $\mathrm{PCR}$ product representing a heteroduplex XBP-1 cDNA species [30]. In all cases, XBP1 activation was then expressed relative to that seen in control THP-1Mon cells.

For gene expression assays, expression of genes of interest (see below) was determined using $\mathrm{SYBR}^{\circledR}$ Green or Taqman ${ }^{\circledR}$ Gene Expression Assays and an Applied Biosystems 7500 Real-time PCR system (Applied Biosystems, Warrington, UK). In the case of MR, IL-1Ra and CHOP, semi-quantitative (relative to $\beta$-actin and/or Glyceraldehyde Phosphate Dehydrogenase (GAPDH)) SYBR $^{\circledR}$ Green assays were carried out using the following primers:

MR: Fwd: 5'-CCATGGACAATGCGCGAGCG-3'

\section{Rev: 5'-CACCTGTGGCCCAAGACACGT-3'}

IL-1Ra: Fwd: 5'-GGCCTCCGCAGTCACCTAATCAC-3'

Rev: 5'-GGACAGGCACATCTTCCCTCCAT-3'

CHOP: Fwd: 5'-GCGTCTAGAATGGCAGCTGAGTCATTGCC-3'

\section{Rev: 5'-GCGTCTAGATCATGCTTGGTGCA-} GATTC-3'

-actin: Fwd: 5'-TCCTGTGGCATCCACGAA-3'

Rev: 5'-GAAGCATTTGCGGTGGAC-3'

GAPDH: Fwd: 5'-ATGTTCCAGTATGACTCCACTCACG-3'

\section{Rev: 5'-GAAGACACCAGTAGACTCCACGACA-3'}

In the case of BiP, mRNA expression was assessed semiquantitatively (relative to GAPDH) via Taqman $\left.{ }^{(}\right)$Gene Expression Assays (Applied Biosystems, Warrington, UK) for BiP (Gene Expression Assay Hs99999174_m1) and GAPDH (Gene Expression Assay Hs99999905_m1).

\section{Cell viability and apoptosis Assays}

Cell viability and apoptosis levels within hMФ, hM2M $\Phi$, THP1-Mon, THP1-M2Mon, dTHP1-MФ, and dTHP1M2M $\Phi$ samples ( \pm treatment with oxLDL for $24 \mathrm{~h}$ as described above) was determined using 3-(4, 5Dimethylthiazol-2-yl)-2, 5 diphenyltetrazolium bromide (MTS) and Caspase-Glo 3/7 assays (Promega, Southampton, UK), respectively, according to the manufacturers' instructions. The resulting absorbance or luminescence data was read via Dynex plate-reading spectrophotometer or luminometer (Worthing, UK), respectively.

\section{Statistical analysis}

Data are expressed as mean \pm standard error of the mean. Statistical significance was determined via ANOVA or 2-sample $t$-tests as appropriate; significance levels were set at $P<0.05$ except where stated otherwise. 


\section{Authors' contributions}

SAl undertook the major part of the experimental work, and also participated in writing of the original manuscript. JSR carried out the M2 marker RT-PCR experiments, including design/optimisation of the PCR protocol. MA advised on experimental methodologies (particularly PCRbased work), and acted as reviewer of drafts of the manuscript. AWT advised on experimental methodologies (particularly monocyte/macrophage cell culture), and acted as reviewer of drafts of the manuscript. KM advised on experimental methodologies (particularly statistical analysis and M2 polarisation), and acted as reviewer of drafts of the manuscript. RW acted as corresponding author (ie. was responsible for writing and submitting of the manuscript), carried out overall design and co-ordination of the study, and also contributed towards laboratory work, in particular bioinofrmatics and XBP-1 splicing assays. All authors read and approved the final manuscript.

\section{Competing interests}

The authors declare that they have no competing interests.

Received: 9 September 2011 Accepted: 6 December 2011 Published: 6 December 2011

\section{References}

1. Holvoet $P$, Lee $D$, Steffes $M$, Gross M, Jacobs DR Jr: Association between Circulating Oxidised low-density lipoprotein and incidence of the metabolic syndrome. JAMA 2008, 299(19):2287-2293.

2. Unger RH: Lipotoxic Diseases. Annu Rev Med 2002, 53:319-336.

3. Ross R: Mechanisms of Disease: Atherosclerosis-an inflammatory disease. N Engl J Med 1999, 340(2):115-126.

4. Mosser DM, Edwards JP: Exploring the Full Spectrum of Macrophage Activation. Nature Reviews Immunology 2008, 8:958-69.

5. Hoekstra M, Van Berkel TJC, Van Eck M: Scavenger Receptor BI: a multipurpose player in cholesterol and steroid metabolism. World Journal of Gastroenterology 2010, 16(47):5916-24.

6. Tiwari Rl, Singh V, Barthwal MK: Macrophages: An Elusive yet Emerging Therapeutic Target of Atherosclerosis. Medicinal Research Reviews 2008, 28(4):483-544.

7. Gordon S: Alternative Activation of Macrophages. Nature Reviews Immunology 2003, 3(1):23-35.

8. Bouhlel MA, Derudas B, Rigamonti E, Dievart R, Brozek J, Haulon S, Zawadzki C, Jude B, Torpier G, Marx N, Staels B, Chinetti-Gbaguid G: PPARy activation primes human monocytes into alternative M2 macrophages with anti-inflammatory properties. Cell Metab 2007, 6:137-143.

9. Vats D, Mukundan L, Odegaard Jl, Zhang L, Smith KL, Morel CR, Wagner A Greaves DR, Murray PJ, Chawla A: Oxidative metabolism and PGC-1 beta attenuate macrophage-mediated inflammation. Cell Metab 2006, 4(1):13-24.

10. Odegaard Jl, Ricardo-Gonzalez RR, Goforth MH, Morel CR, Subramanian V, Mukundan L, Red Eagle A, Vats D, Brombacher F, Ferrante AW, Chawla A: Macrophage-specific PPARgamma controls alternative activation and improves insulin resistance. Nature 2007, 447(7148):1116-20.

11. Akiyama TE, Sakai S, Lambert G, Nicol CJ, Matsusue K, Pimprale S, Lee YH, Ricote M, Glass CK, Brewer HB Jr, Gonzalez FJ: Conditional disruption of the peroxisome proliferator-activated receptor gamma gene in mice results in lowered expression of $A B C A 1, A B C G 1$, and apoE in macrophages and reduced cholesterol efflux. Mol Cell Biol 2002, 22(8):2607-19.

12. Lumeng CN, Bodzin JL, Saltiel AR: Obesity Induces a Phenotypic Switch in Adipose Tissue Macrophage Polarisation. J Clin Invest 2007, 117:175-84.

13. Li Y, Schwabe RF, DeVries-Seimon T, Yao PM, Gerbod-Giannone MC, Tall AR, Davis RJ, Flavell R, Brenner DA, Tabas I: Free Cholesterol-loaded Macrophages are an Abundant Source of TNFa and IL-6. J Biol Chem 2005, 280:21763-72.

14. Satoh N, Shimatsu A, Himeno A, Sasaki Y, Yamakage H, Yamada K, Suganami T, Ogawa Y: Unbalanced M1/M2 phenotype of peripheral blood monocytes in obese diabetic patients: effect of pioglitazone. Diabetes Care 2010, 33(1):e7.

15. Prieur X, Mok CY, Velagapudi VR, Núñez V, Fuentes L, Montaner D, Ishikawa K, Camacho A, Barbarroja N, O'Rahilly S, Sethi JK, Dopazo J, Orešič $M$, Ricote $M$, Vidal-Puig A: Differential lipid partitioning between adipocytes and tissue macrophages modulates macrophage lipotoxicity and M2/M1 polarization in obese mice. Diabetes 2011, 60(3):797-809.
16. Li Y, Ge M, Ciani L, Kuriakose G, Westover EJ, Dura M, Covey DF, Freed JH, Maxfield FR, Lytton J, Tabas I: Enrichment of Endoplasmic Reticulum with Cholesterol inhibits Sarcoplasmic-endoplasmic reticulum calcium ATPase activity in Parallel with increased order of Membrane lipids: Implications for depletion of Endoplasmic reticulum calcium stores and apoptosis in cholesterol-loaded macrophages. J Biol Chem 2004, 279(35):37030-37039.

17. Sidrauski C, Chapman R, Walter P: The unfolded protein response: an intracellular signalling pathway with many surprising features. Trends Cell Biol 1998, 8:245-249.

18. Yoshida H, Haze K, Yanagi H, Yura T, Mori K: Identification of the cis-acting endoplasmic reticulum stress response element responsible for transcriptional induction of mammalian glucose-regulated proteins. Involvement of basic leucine zipper transcription factors. J Biol Chem 1998, 273(50):33741-33749.

19. Oyadomari S, Mori M: Roles of CHOP/GADD153 in endoplasmic reticulum stress. Cell Death Differ 2004, 11(4):381-9.

20. DeVries-Seimon T, Li Y, Yao PM, Stone E, Wang Y, Davis RJ, Flavell R, Tabas I: Cholesterol-induced macrophage apoptosis requires ER stress pathways and engagement of the type A scavenger receptor. J Cell Biol 2005, 171(1):61-73.

21. Tsukano H, Gotoh T, Endo M, Miyata K, Tazume H, Kadomatsu T, Yano M, Iwawaki T, Kohno K, Araki K, Mizuta H, Oike Y: The endoplasmic reticulum stress-C/EBP homologous protein pathway-mediated apoptosis in macrophages contributes to the instability of atherosclerotic plaques. Arterioscler Thromb Vasc Biol 2010, 30(10):1925-32.

22. Sanson M, Auge N, Vindis C, Muller C, Bando Y, Thiers J-C, Marachet M-A, Zarkovic K, Sawa Y, Salvayre R, Negre-Salvayre A: Oxidized Low-density lipoproteins trigger endoplasmic reticulum stress in vascular cells: Prevention by oxygen-regulated protein 150 expression. Circ Res 2009, 104(3):328-336.

23. Isa S: The Impact of Natural and Synthetic PPARy Ligands on ER stress and the UPR PhD Thesis, University of Wales, UK; 2011.

24. Hitomi J, Katayama T, Taniguchi M, Honda A, Imaizumi K, Tohyama M: Apoptosis Induced by Endoplasmic Reticulum Stress depends on Activation of Caspase-3 via caspase-12. Neurosci Lett 2004, 357(2):127-130.

25. Garcia-Calvo M, Peterson EP, Rasper DM, Vaillancourt JP, Zamboni R, Nicholson DW, Thornberry NA: Purification and Catalytic Properties of Human Caspase Family Members. Cell Death Differ 1999, 6(4):362-369.

26. Tsuchiya S, Yamabe M, Yamaguchi Y, Kobayashi Y, Konno T, Tada K: Establishment and Characterization of a Human Acute Monocytic Leukemia Cell line (THP-1 cells). Int J Cancer 1980, 26(2):171-176.

27. Grynkiewicz G, Poenie M, Tsien RY: A new generation of $\mathrm{Ca} 2+$ indicators with greatly improved fluorescence properties. J Biol Chem 1985, 260:3440-3450.

28. Merritt JE, McCarthy SA, Davies MP, Moores KE: Use of fluo-3 to measure cytosolic $\mathrm{Ca}^{2+}$ in platelets and neutrophils Loading cells with the dye, calibration of traces, measurements in the presence of plasma, and buffering of cytosolic Ca ${ }^{2+}$. Biochem J 1990, 269:513-519.

29. Caddy J, Webb R: Rosiglitazone induces the unfolded protein response, but has no significant effect on cell viability, in monocytic and vascular smooth muscle cells. Biochem Biophys Res Comm 2010, 400:689-695.

30. Shang J: Quantitative Measurement of events in the mammalian unfolded protein response. Methods 2005, 35(4):390-394.

31. Butcher L, Thomas AW, Backx K, Roberts AW, Webb R, Morris K: Lowintensity exercise exerts beneficial effects on plasma lipids via PPAR $\gamma$. Med Sci Sports Ex 2008, 40(7):1-7.

32. Werb Z, Cohn ZA: Cholesterol Metabolism in the Macrophage. J Exp Med 1971, 135:21-44.

33. Lodish H, Berk A, Matsudaira P, Kaiser CA, Krieger M, Scott MP, Zipursky SL, Darnell J: Molecular Cell Biology. 5 edition. WH Freeman \& Co, New York; 2004, 53.

34. Munafo DB, Colombo Ml: A novel assay to study autophagy: regulation of autophagosome vacuole size by amino acid deprivation. I Cell Sci 2007, 114(pt 20):3619-3629.

35. Hoyer-Hansen M, Jaattela M: Connecting endoplasmic reticulum stress to authopagy by unfolded protein response and calcium. Cell Death Diff 2007, 14(9):1576-1582.

36. Mandal P, Pratt BT, Barnes M, McMullen MR, Nagy LE: Molecular mechanism for adiponectin-dependent M2 macrophage polarization: link between the metabolic and innate immune activity of full-length adiponectin. J Biol Chem 2011, 286(15):13460-9. 
37. Iwashima Y, Eto M, Hata A, Kaku K, Horiuchi S, Ushikubi F, Sano H Advanced Glycation End Products-Induced Gene Expression of Scavenger Receptors in Cultured Human Monocyte-Derived Macrophages. Biochem Biophys Res Comm 2000, 277:368-380.

38. Tjiu JW, Chen JS, Shun CT, Lin SJ, Liao YH, Chu CY, Tsai TF, Chiu HC, Dai YS,

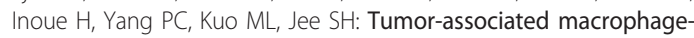
induced invasion and angiogenesis of human basal cell carcinoma cells by cyclooxygenase-2 induction. J Invest Dermatol 2009, 129(4):1016-1025.

39. Taketa K, Matsimura T, Yano M, Ishii N, Senokuchi T, Motoshima H,

Murata Y, Kim-Mitsuyama S, Kawada T, Itabe H, Takeya M, Nishikawa T, Tsuruzoe K, Araki E: Oxidized Low Density Lipoprotein Activates PPARa and PPARY through MAPK-dependent COX-2 Expression in Macrophages. J Biol Chem 2008, 283(15):9852-9862.

doi:10.1186/1476-511X-10-229

Cite this article as: Isa et al:: M2 macrophages exhibit higher sensitivity to oxLDL-induced lipotoxicity than other monocyte/macrophage subtypes. Lipids in Health and Disease 2011 10:229.

\section{Submit your next manuscript to BioMed Central} and take full advantage of:

- Convenient online submission

- Thorough peer review

- No space constraints or color figure charges

- Immediate publication on acceptance

- Inclusion in PubMed, CAS, Scopus and Google Scholar

- Research which is freely available for redistribution

Submit your manuscript at www.biomedcentral.com/submit
Ciomed Central 